\title{
The origin and significance of early Archean hydrothermal barite
}

\author{
DESIREE L. ROERDINK ${ }^{1}$, PAUL R. D. MASON ${ }^{2}$, MARK \\ VAN ZUILEN ${ }^{3}$ AND DYLAN T. WILMETH $^{4}$
}

\author{
${ }^{1}$ University of Bergen \\ ${ }^{2}$ Utrecht University \\ ${ }^{3}$ Institut de Physique du Globe de Paris \\ ${ }^{4}$ CNRS-UMR6538 Laboratoire Géosciences Océan \\ Presenting Author: desiree.roerdink@uib.no
}

Sulfate minerals are rare in the rock record prior to the oxygenation of the atmosphere 2.4 billion years ago consistent with the estimated near absence of sulfate in Archean seawater. Exceptions include isolated occurrences of Paleoarchean barite found in volcano-sedimentary successions in Australia, India and South Africa. This period of barite deposition from 3.5-3.2 Ga was intermittent and localized with volcanic outgassing of $\mathrm{SO}_{2}$ and seafloor hydrothermal activity as most likely sources of sulfate and barium [1]. However, the origin and paleoenvironmental significance of the barite remains controversial despite several decades of study. Resolving these issues has wider scientific implications, for example for the interpretation of sulfur isotope data as evidence for early microbial sulfur cycling in barite-rich Archean environments [24] or the use of strontium isotopes as recorder of early crustal weathering processes [5]. Here we discuss the formation pathway of 3.26-3.23 Ga barite deposits in the Barberton Greenstone Belt in South Africa based on field and geochemical data. We report evidence for primary precipitation of barite onto the sedimentary substrate and find a close association between barite and chert precipitation. Host rocks and cross-cutting chert dykes are enriched in barium but lack elevated concentrations of copper and zinc, consistent with the absence of high-temperature massive sulfide deposits. Rare earth element (REE) patterns in cherts do not show strong light REE enrichments or Eu anomalies that are typical for high-temperature hydrothermal settings, and feeder chert dykes have seawater-like REE abundances. These findings support a marine setting with lowtemperature hydrothermal activity. Evidence for low-temperature alteration and silicification was also found at a $3.52 \mathrm{Ga}$ barite deposit in Eswatini that occurs in a succession of mafic and felsic volcanic rocks, suggesting that this mechanism of barite formation may have been dominant throughout the Paleoarchean in sulfate-rich environments in the Barberton Greenstone Belt.

[1] Lowe et al (2019) Precam. Res., 327, 34-46; [2] Shen et al (2001) Nature, 410, 77-81; [3] Philippot et al (2007) Science, 317, 1534-1537; [4] Roerdink et al (2012) EPSL, 331-332, 177186; [3] Satkoski et al (2016) EPSL, 454, 28-35 